\title{
Hardware Testing of Photovoltaic Inverter Loss of Mains Protection Performance
}

\author{
I Abdulhadi*, A Dyśko ${ }^{\dagger}$ \\ *Power Networks Demonstration Centre,UK, ibrahim.f.abdulhadi@strath.ac.uk \\ ${ }^{\dagger}$ University of Strathclyde, UK, a.dysko@strath.ac.uk
}

Keywords: Photovoltaic inverters, loss of mains protection, grid resilience, hardware testing.

\begin{abstract}
This paper presents the findings from hardware testing of photovoltaic inverters in a realistic low voltage network setting. The objective of the tests was to evaluate the performance of inverter built-in loss of mains protection. The evaluation focuses on ensuring that this protection operates as expected during islanding situations, while avoiding spurious tripping during severe grid disturbances.
\end{abstract}

\section{Introduction}

Failure of Loss of Mains (LoM) protection to detect an unintended islanding condition of distributed generation (DG) can increase the risk of exposing personnel to safety hazards as well as cause damage to generators [1]. An equally undesirable behaviour of LoM protection may occur during grid wide disturbances which may cause spurious tripping of LoM protection. This presents a challenge for selecting a suitable LoM setting or implementing a reliable LoM algorithm. A particular challenge presents itself with inverter interfaced generation where the behaviour of the inverter is not very well understood under islanding or grid disturbance conditions and can vary widely between different manufacturers. Furthermore, there is no widely accepted model of behaviour for these inverters' controllers or built-in protection algorithms. Currently the connection requirements for such inverters specified in the engineering recommendation G83/2 [3] only guarantees the inverter connection stability under system disturbances with rates of change of frequency up to $0.2 \mathrm{~Hz} / \mathrm{s}$.

To this end, physical testing of inverters under anticipated future conditions reaching outside of G83 requirements becomes more favourable. As such, this paper presents the results of network testing of low voltage (LV) photovoltaic (PV) inverters to determine the performance under islanding and grid disturbances, specifically:

- To establish the existence and quantify the non-detection zone (NDZ) of inverter LoM protection;

- To assess the stability of inverter connection to the grid during frequency and voltage phase shift disturbances, which may be compromised by the inverter LoM protection or controls.

A range of commercially available PV inverters were tested to ensure that a representative behaviour is observed. Tested inverters are compliant with the UK engineering recommendations G59 and G83 for the connection of generation to the distribution network $[2,3]$. The testing was conducted at the Power Networks Demonstration Centre (PNDC) [4].

The outcomes of these tests feed into the UK joint transmission/distribution code review panel activities, which assesses the impact of large disturbances on system frequency [5]. Such impact will become more pronounced with more generation being connected to the grid via inverter interfaces and overall lowering of system inertia. It is, therefore, crucial that the continuity of power generation from small scale inverters during system wide events is preserved. Through hardware testing of typical inverters under realistic system conditions this paper aims to establish any potential risks associated with high penetration levels of inverter connected PV generation.

\section{Test setup}

Table 1 lists the PV inverters that were tested at the PNDC. Some of the inverters can have G83 or G59 settings activated as required. However, the table shows the active settings during testing.

\begin{tabular}{|c|c|c|c|}
\hline Phases & PV Inverter & $\begin{array}{c}\text { Maximum } \\
\text { AC Power } \\
\text { Rating } \\
\end{array}$ & $\begin{array}{c}\text { Active } \\
\text { settings } \\
\text { during testing }\end{array}$ \\
\hline \multirow{4}{*}{$\begin{array}{l}\text { Single } \\
\text { Phase }\end{array}$} & $\begin{array}{l}\text { ABB PVI- } \\
\text { 5000-TL- } \\
\text { OUTD* }\end{array}$ & $5.56 \mathrm{kVA}$ & G59/3 \\
\hline & $\begin{array}{l}\text { SMA Sunny } \\
\text { Boy 5000TL* }\end{array}$ & $5.0 \mathrm{kVA}$ & G59/3 \\
\hline & $\begin{array}{c}\text { Kaco Powador } \\
6002\end{array}$ & $5.0 \mathrm{kVA}$ & G59/2 \\
\hline & $\begin{array}{l}\text { Fronius IG } \\
\text { Plus } 30 \mathrm{~V}-1\end{array}$ & $3.0 \mathrm{kVA}$ & G83/1 \\
\hline $\begin{array}{l}\text { Three } \\
\text { Phase }\end{array}$ & $\begin{array}{c}\text { SMA } \\
\text { Tripower } \\
\text { 10000TL* }\end{array}$ & $10.0 \mathrm{kVA}$ & G59/3 \\
\hline
\end{tabular}

Table 1: List of PV inverters under test (*inverters marked have a transformer-less interface to the LV grid) 
$5 \mathrm{~kW}$ Chroma 62050H [6] PV emulators were used to drive the inverters. The emulators output the desired DC power according to EN50530 to achieve maximum power point tracking (MPPT) [7]. Two emulators were used to drive up to two single phase inverters simultaneously. The following subsections describe the tests performed which are grouped into three test categories.

\subsection{Test category 1: islanding sensitivity}

Figure 1 shows the network configuration for conducting genuine islanding tests. The network is supplied via a motorgenerator $(\mathrm{M}-\mathrm{G})$ set at $11 \mathrm{kV}$. The inverters are connected to the LV network where a controllable resistive-inductive (RL) load bank is also connected. Islanding of the inverters and load bank is achieved by opening a switch designated as the point of common coupling (PCC). A calibrated power quality meter is used to measure the current and voltage at the PCC and inverter outputs.

The purpose of this test is to ensure that the LoM protection of the inverters operates successfully, especially when the pre-LoM power flow across the PCC is very small. The power flow through the PCC is reduced to the lowest possible value by adjusting both the power output of the inverters and the load bank power consumption.

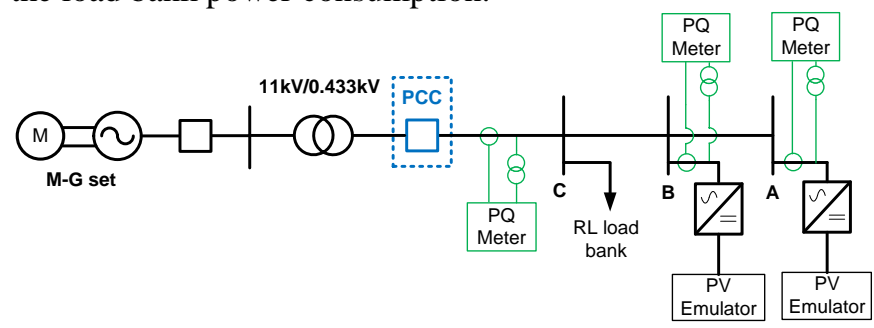

Figure 1: Network configuration for test category 1

\subsection{Test category 2: stability against RoCoF disturbances}

The purpose of this test is to ensure that the inverters do not spuriously disconnect from the grid during a severe rate of change of frequency (RoCoF) event. A $1 \mathrm{~Hz} / \mathrm{s}$ (accelerating and decelerating) RoCoF event is achieved by controlling the speed set point of the M-G set (refer to Figure 2). The network is instrumented as in test category 1 to monitor the behaviour of the inverters during this test.

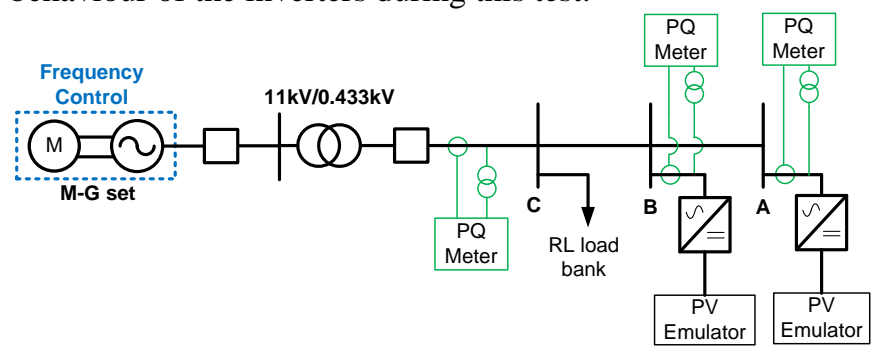

Figure 2: Network configuration for test category 2

Typical frequency profiles during accelerating and decelerating RoCoF tests are shown in Figure 3 and Figure 4 respectively. Note that the frequency bands containing the RoCoF events are selected to ensure that the inverters' over and under frequency protection does not operate.

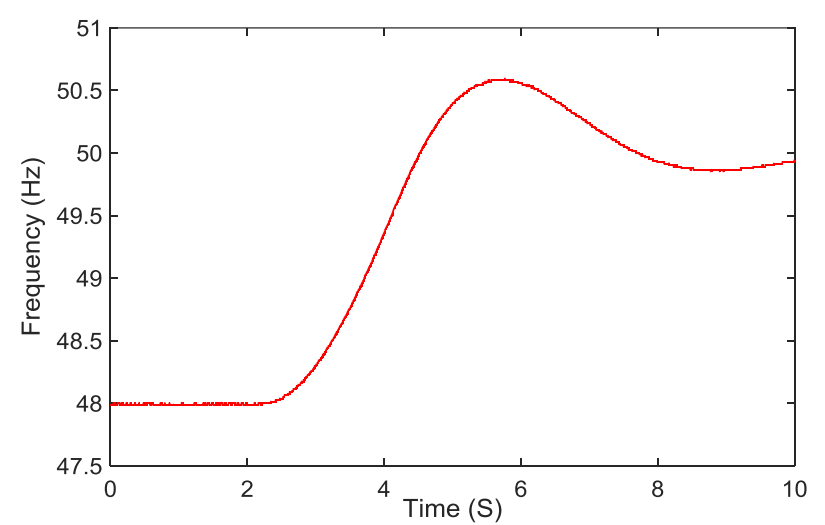

Figure 3: Frequency profile during accelerating RoCoF test

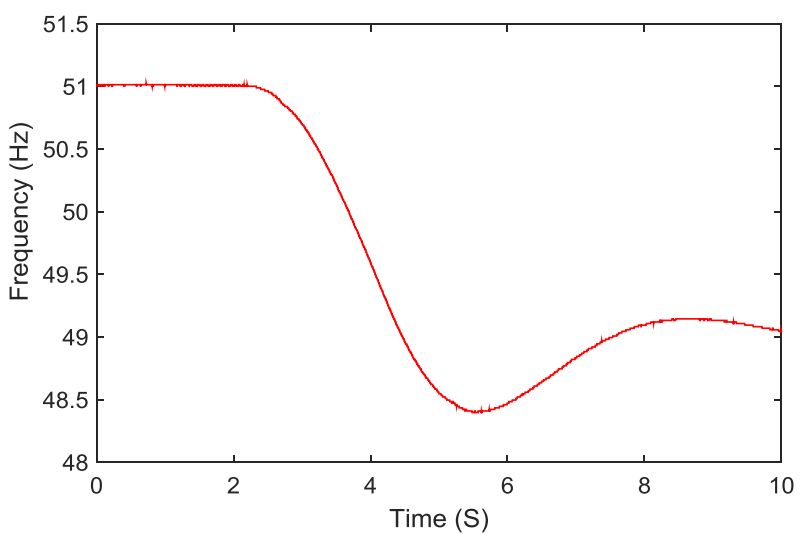

Figure 4: Frequency profile during decelerating RoCoF test

In order to verify that the obtained frequency profile does indeed produce the desired $\mathrm{RoCoF}$, a sample of measured instantaneous voltage was injected into a commercial RoCoF protection relay. The relay reported $1.35 \mathrm{~Hz} / \mathrm{s}$ on average from two sample voltage injections. This is deemed acceptable for the testing.

\subsection{Test category 3: stability against simultaneous voltage phase shift and RoCoF disturbances}

The purpose of this test category is to ensure that the inverters remain synchronised to the grid during a simultaneous RoCoF and voltage phase shift event. Such disturbance emulates a grid event where large loss of generation is accompanied by a change in grid bus voltage angle which is typical of the locations in the proximity of a major transmission system fault.

Figure 5 shows the network configuration during this test category. The M-G speed is controlled to initially introduce a drop in frequency at a rate of $0.5 \mathrm{~Hz} / \mathrm{s}$. After $0.5 \mathrm{~s}$ of initiating the frequency drop, a phase-phase LV fault is introduced to the system. Introducing this fault aims to produce sufficient step change in reactive power flow in the system to create a sudden shift in voltage phase angle together with the network frequency drop.

A typical frequency profile obtained during this test is shown in Figure 6. The obtained RoCoF and voltage phase shift was verified as in test category 2. The LoM relay reported an average phase shift of $6.5^{\circ}$ from two sample voltage 
injections. The measured RoCoF increased after the introduction of the $\mathrm{LV}$ fault to $5.5 \mathrm{~Hz} / \mathrm{s}$.

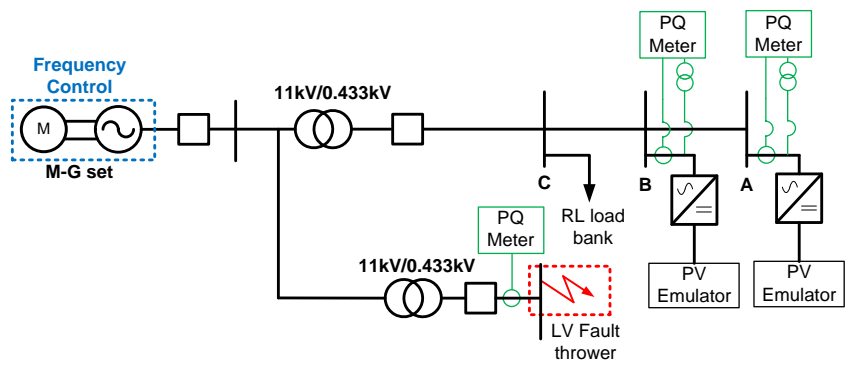

Figure 5: Network configuration for test category 3

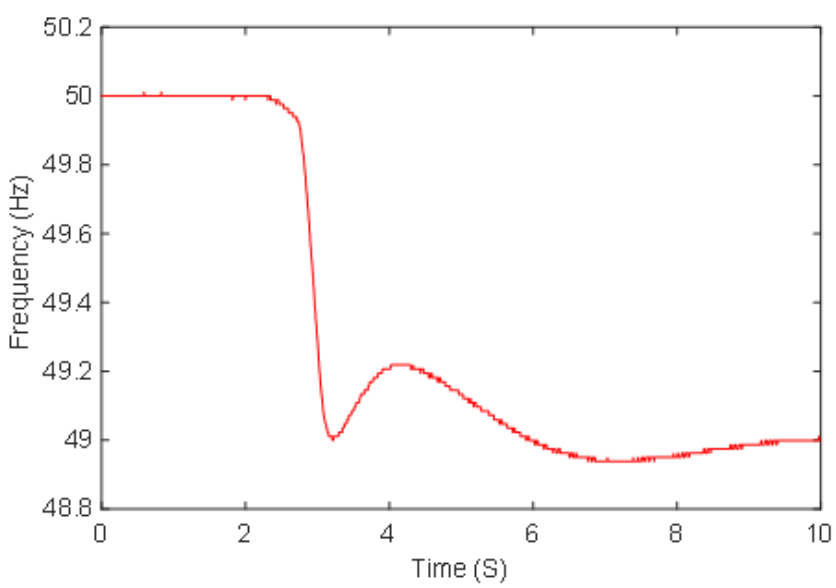

Figure 6: Typical frequency profile during category 3 tests

Figure 7 shows the physical test setup at the PNDC where the inverters are connected to the facilitiy's LV network.

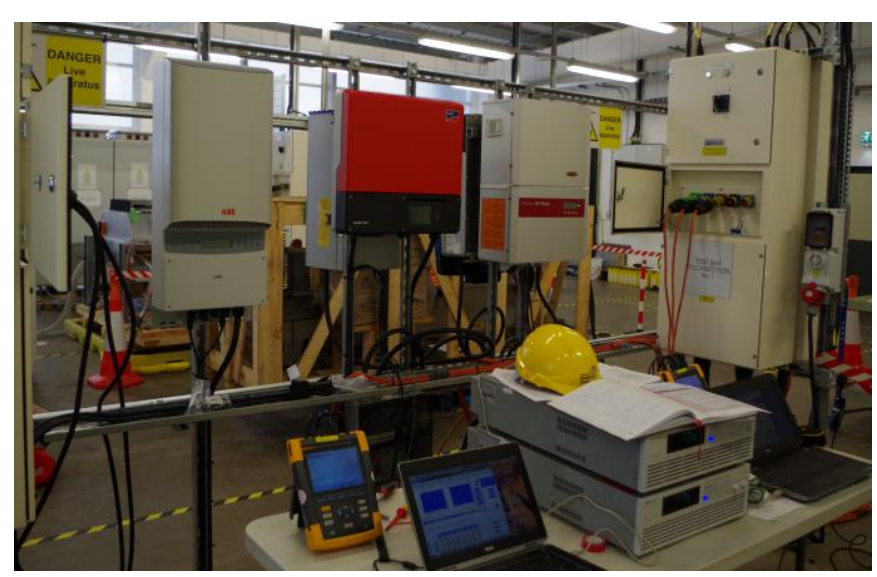

Figure 7 Inverter testing setup at the PNDC

\section{Inverter performance evaluation}

The main findings from the tests are presented in this section. Due to the lack of space, only a selection of the recorded measurements will be presented to enforce the main findings.

\subsection{Test category 1 results and evaluation}

Active power flow achieved through the PCC for all tests was less than $1 \%$ of the connected inverter $\mathrm{kVA}$ rating. The reactive power flow was more difficult to minimise due to the inverters exporting a minimum amount of reactive power while generating, as well as the combined reactance of the cable and overhead line circuits in the test network. All inverters disconnected successfully for LoM tests. This holds for both tests where inverters were connected individually or in pairs to the LV network. The pre-LoM event power flows and average disconnection times are summarised in Table 2. The direction of power flow across the PCC is positive for active and reactive power flow towards the load. The disconnection time is defined as the period between the opening of the PCC and the tripping of the inverter. The latter is determined from the collapse of the inverter output current to zero. The average times are calculated from two measurements.

\begin{tabular}{|c|c|c|c|c|}
\hline \multirow{2}{*}{$\begin{array}{c}\text { Inverter } \\
1\end{array}$} & \multirow{2}{*}{$\begin{array}{c}\text { Inverter } \\
2\end{array}$} & \multicolumn{2}{|c|}{$\begin{array}{l}\text { PCC power flow } \\
\text { prior to islanding }\end{array}$} & \multirow{2}{*}{$\begin{array}{c}\text { Average } \\
\text { inverter } \\
\text { disconnection } \\
\text { time (s) }\end{array}$} \\
\hline & & $\begin{array}{c}\text { Active } \\
\text { Power } \\
\text { (W) }\end{array}$ & $\begin{array}{c}\text { Reactive } \\
\text { Power } \\
\text { (VAr) }\end{array}$ & \\
\hline $\mathrm{ABB}$ & & -10 & -10 & 0.406 \\
\hline Kaco & & 20 & 10 & 0.9 \\
\hline Fronius & & -2 & 143 & 0.275 \\
\hline $\begin{array}{l}\text { SMA (1 } \\
\text { phase) }\end{array}$ & & 0 & -10 & 0.123 \\
\hline $\begin{array}{c}\text { SMA (3 } \\
\text { phase) }\end{array}$ & & -40 & 40 & 0.126 \\
\hline $\mathrm{ABB}$ & $\begin{array}{l}\text { SMA (1 } \\
\text { phase) }\end{array}$ & 0 & -50 & 0.324 \\
\hline $\mathrm{ABB}$ & Kaco & 0 & 20 & 0.493 \\
\hline Fronius & Kaco & 0 & -160 & 0.465 \\
\hline Kaco & $\begin{array}{l}\text { SMA (1 } \\
\text { phase) }\end{array}$ & -10 & 30 & 0.458 \\
\hline
\end{tabular}

Table 2: Summary of category 1 test results

Figures 8 to 10 show the output voltage and current of the ABB, Fronious and SMA (3-phase) inverters during the islanding test. The period between LoM initiation and inverter disconnection is marked with vertical black lines on the waveforms. The behaviour of the inverters varies slightly between a sudden or gradual collapse of output voltage.

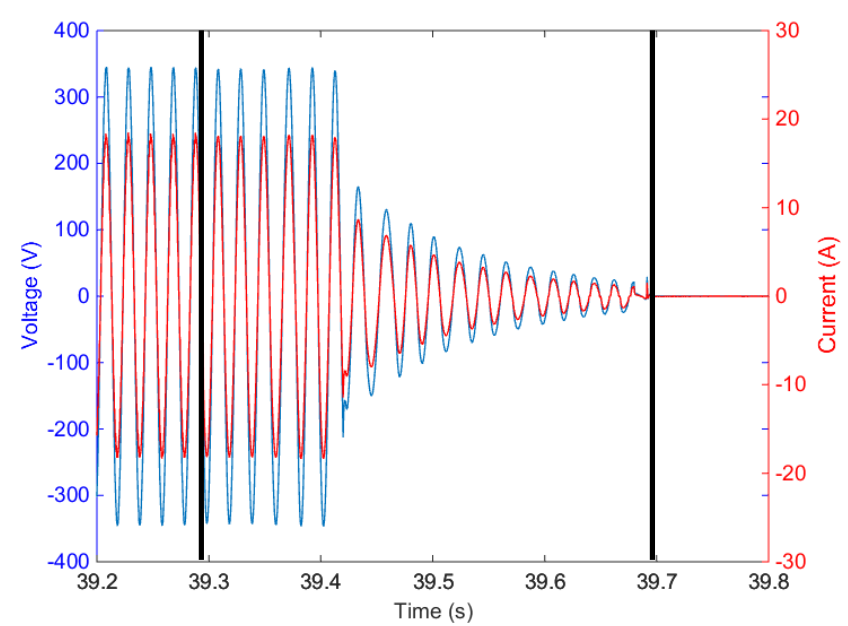

Figure 8: Output of $\mathrm{ABB}$ inverter during islanding test 


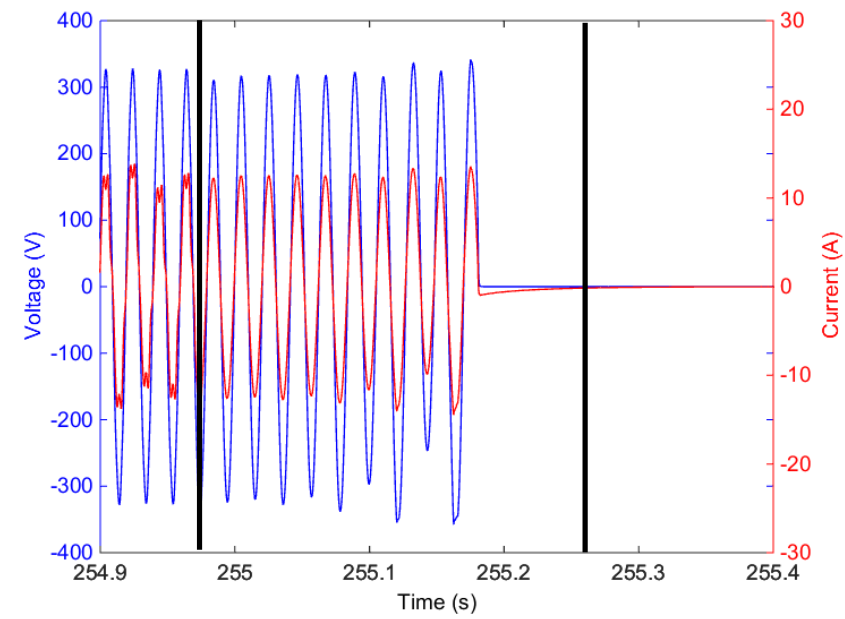

Figure 9: Fronius inverter output during islanding test

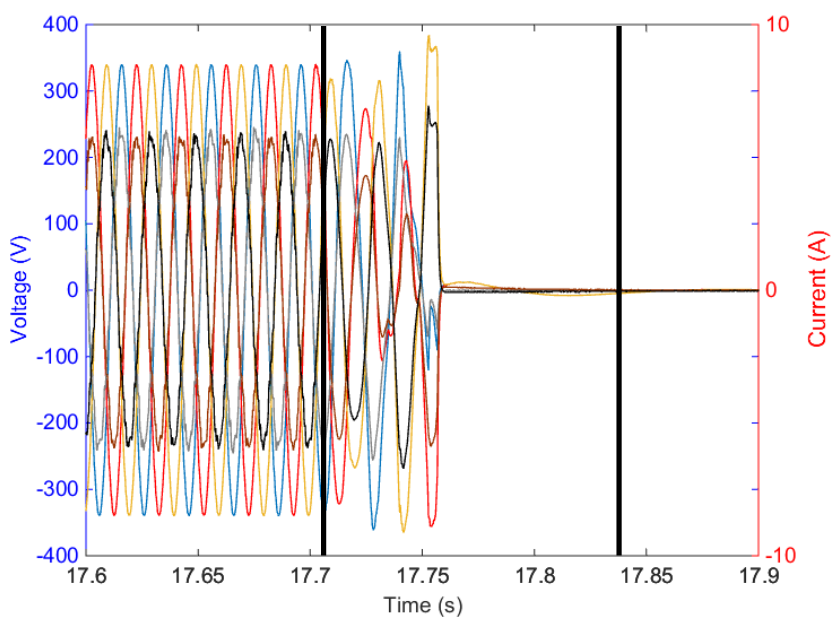

Figure 10: SMA 3-phase inverter output during islanding test

\subsection{Test category 2 results and evaluation}

During this test, all inverters remained synchronised to the grid. However, the behaviour of the inverters in terms of power output during this test varies.

Transformer-less inverters exhibit a momentary change in reactive power output. A positive RoCoF event results in the inverter absorbing reactive power, while additional reactive power is exported during a negative RoCoF event. The extent and duration of this change depends on the inverter and severity of the RoCoF event. Figure 11 shows an example of this where the SMA (1-phase inverter) absorbs around $1 \mathrm{kVAr}$ during at $+1 \mathrm{~Hz} / \mathrm{s}$ disturbance. Note that the power measurements provided by the power quality meter are $0.25 \mathrm{~s}$ averages. Inverters with a transformer interface (i.e. Kaco and Fronious) do not exhibit a significant change in reactive power output. An example of this is depicted in Figure 12 which shows the power output of the Kaco inverter during a $+1 \mathrm{~Hz} / \mathrm{s}$ event.

In addition to the reactive power output change, the $\mathrm{ABB}$ inverter active output is reduced under certain circumstances. It was observed that the active power output of the inverter is reduced to zero for $1 \mathrm{~s}$ when a system RoCoF of $1 \mathrm{~Hz} / \mathrm{s}$ is applied over a $2 \mathrm{~Hz}$ band (e.g. between 51-49 Hz). This reduction of active power is illustrated Figure 13. Further testing determined that a minimum disturbance of $0.7 \mathrm{~Hz} / \mathrm{s}$ over a frequency band of $1.5 \mathrm{~Hz}$ is required before the $\mathrm{ABB}$ inverter starts exhibiting this power drop (see Figure 14). Otherwise, with lower RoCoF values, the active power output of the inverter remains largely stable (see Figure 15 for a $0.6 \mathrm{~Hz} / \mathrm{s}$ disturbance). This drop in active power output may only be a cause of concern if a large number of them were connected to the grid and experience a frequency drop of around $1.5 \mathrm{~Hz}$ (i.e. down to $48.5 \mathrm{~Hz}$ ) at a rate of $0.7 \mathrm{~Hz} / \mathrm{s}$. At this point, low frequency load shedding would operate to recover the system frequency.

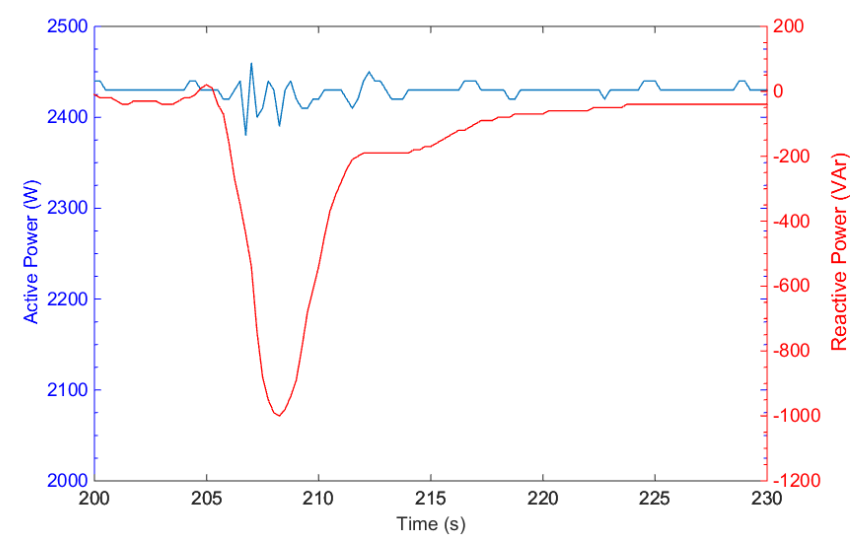

Figure 11: SMA 1-phase inverter output during $+1 \mathrm{~Hz} / \mathrm{s}$ test

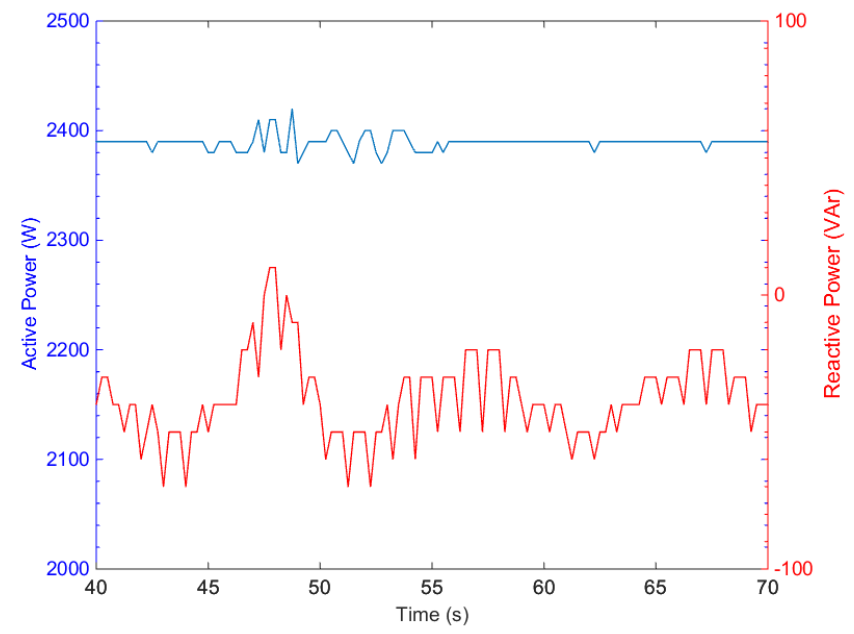

Figure 12: Kaco inverter output during $+1 \mathrm{~Hz} / \mathrm{s}$ test

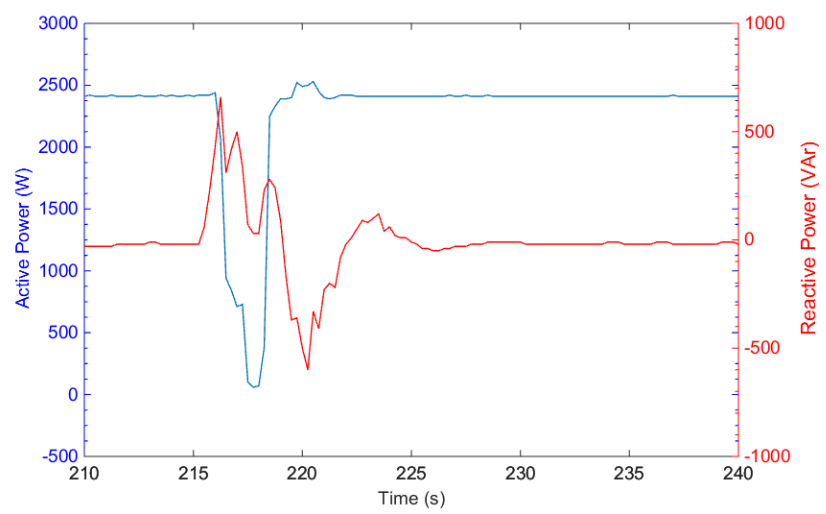

Figure 13: ABB inverter output during $-1 \mathrm{~Hz} / \mathrm{s}$ RoCoF test 


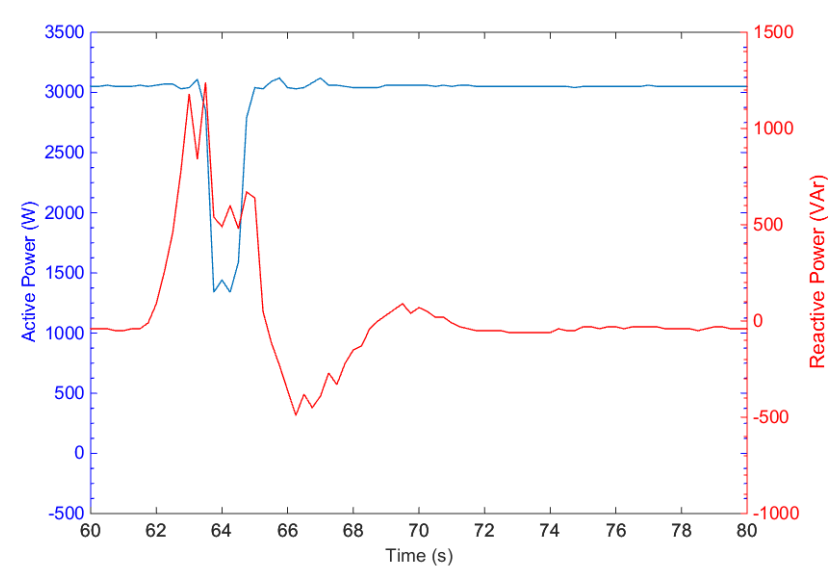

Figure 14: ABB inverter output during - $0.7 \mathrm{~Hz} / \mathrm{s}$ RoCoF over a $1.5 \mathrm{~Hz}$ band test

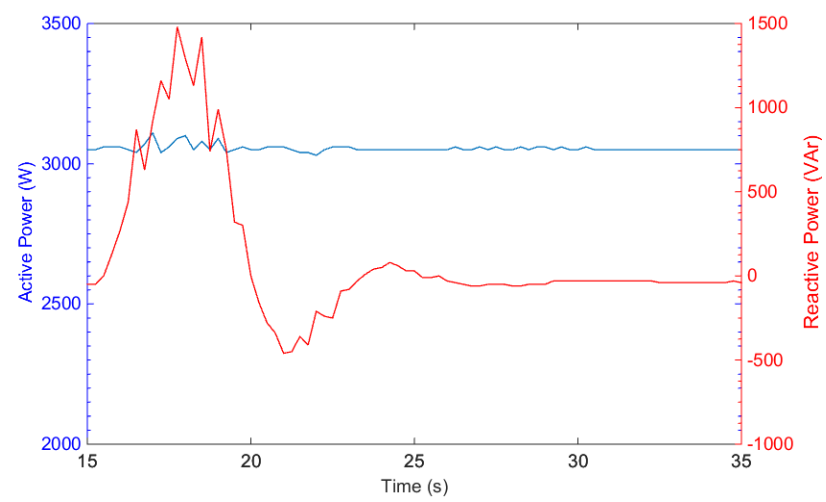

Figure 15: ABB inverter output during $-0.6 \mathrm{~Hz} / \mathrm{s}$ RoCoF test

\subsection{Test category 3 results and evaluation}

Figure 16 shows the voltage and current output of the Kaco inverter during this test. The voltage phase shift and subsequent shift in current phase during the fault inception can be observed in the figure. A change in inverter power factor is also observed prior to the fault due to the change in reactive power output during the initial frequency drop as shown in category 2 tests.

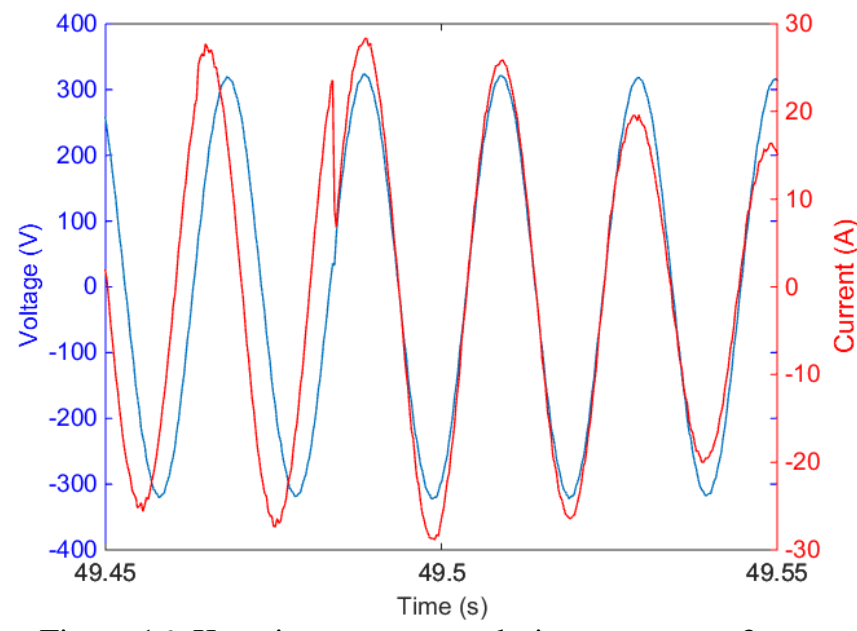

Figure 16: Kaco inverter output during a category 3 test
The inverter also contributes a small amount of fault current. Quantifying the fault current contribution of the inverters is out with the scope of this paper.

Figure 17 shows the output of the ABB inverter during the same test. Similar voltage and current phase shifts can also be observed.

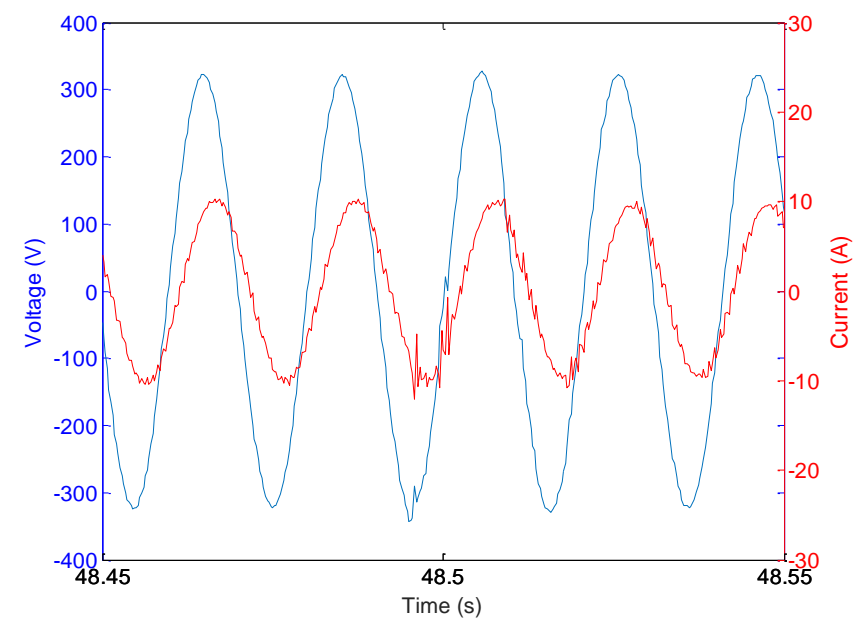

Figure 17 ABB inverter output during a category 3 test

All inverters remained synchronised to the grid during this test category.

\section{Conclusion}

Based on the testing conditions, tested inverters and observations, it can be concluded that there is no NDZ associated with the inverters during islanding. However, it is difficult to generalise this finding onto a network with a large number of inverter interfaced generation, especially when mixed with other generating technologies. This warrants further investigation where multiple inverters could be connected to the LV test network.

The tests have confirmed that the inverters are able to remain synchronised with the grid under RoCoF events of up to $1.35 \mathrm{~Hz} / \mathrm{s}$ measured over a $2 \mathrm{~Hz}$ frequency deviation band. Introducing a voltage phase shift of up to $6.5^{\circ}$ during an initial $0.5 \mathrm{~Hz} / \mathrm{s}$ grid frequency drop did not result in inverter disconnection either.

Some variations in inverter output during testing implies subtleties in implemented inverter controls. These manifest themselves in the way inverter output voltage collapses after islanding and in changes in the active and reactive power output during RoCoF disturbances. However, none of these small control implementation differences seem to have a notable impact on the sensitivity of LoM detection or stability under other tested disturbances.

\section{Acknowledgements}

The Authors would like to thanks the Energy Networks Association and particularly the UK National Grid for their funding and support while conducting this project. 


\section{References}

[1] Energy Networks Association, "ENA ETR 139: Recommendations for Setting of Loss of Mains Protection Relays," 2009.

[2] Energy Networks Association, "Engineering Recommendation G59, Issue 3: Recommendations for the Connection of Generating Plant to the Distribution Systems of Licensed Distribution Network Operators," 2013.

[3] Energy Networks Association, "ER G83/2: Recommendations for the Connection of Type Tested Small-scale Embedded Generators (Up to 16A per Phase) in Parallel with Low-Voltage Distribution Systems," 2012.

[4] C. D. Booth, F. Coffele, and G. M. Burt, "The Power Networks Demonstration Centre: An environment for accelerated testing, demonstration and validation of existing and novel protection and automation systems," in DPSP 2014, 2014, pp. 1-6.

[5] National Grid, GC0035 / GC0079 Frequency Changes during Large Disturbances and their effect on the total system - Phase 1 \& 2. Available: http://goo.gl/H2ZMVr

[6] Chroma, "Programmable DC Power Supply with Solar Array Simulation: Model 62000H-S Series Data Sheet," Available: http://www.chromaate.com

[7] British Standards, "BS EN 50530:2010+A1:2013 Overall Efficiency of Grid Connected Photovoltaic Inverters," 2013. 